\title{
Sebuah Studi Psikologis Terhadap Proses Idolisasi Remaja Terhadap Idola K-Pop (Korean Pop)
}

\author{
Hanno Avila Pradata \\ Fakultas Psikologi, Universitas Surabaya \\ tujuhbelassepuluh@gmail.com
}

\begin{abstract}
This research based on $K$-pop music phenomenon which a trend among Indonesian's teenagers. The beginning process, what idol meant to fans and their impact on fans' life are the focuses on this research. This research uses qualitative methods and interpretive phenomenological analysis as design. Research shows that there was a stimulation to began the musical interest from the family and this stimulation grows as reinforcement, given especially by mother's side. There's also obstacles that came from father's side which reacted by participants by crying and lying. Participants said that emotional and instrumental support given by family or friends, reinforced ther idolization behaviour but they also received bullying from their school's mate because their K-pop idols looked so feminine. Participant's fanatism to idols was reinforced and led to a condition called internalization. This internalization condition led them to have sexual fantasies towards the idol and beliefs that idols are their boyfriends.
\end{abstract}

Keywords: idolization process; phenomenological; k-pop; idol; meaning and beliefs; fantasy.

\begin{abstract}
Abstrak
Penelitian ini didasarkan pada fenomena musik K-pop yang menjadi tren di kalangan remaja Indonesia. Proses awal, apa arti idola bagi penggemar dan dampaknya terhadap kehidupan penggemar adalah fokus pada penelitian ini. Penelitian ini menggunakan metode kualitatif dan analisis fenomenologis interpretatif sebagai desain. Penelitian menunjukkan bahwa ada stimulasi untuk memulai minat musik dari keluarga dan stimulasi ini tumbuh sebagai penguatan, yang diberikan terutama oleh pihak ibu. Ada juga hambatan yang datang dari sisi ayah yang bereaksi oleh peserta dengan menangis dan berbohong. Peserta mengatakan bahwa dukungan emosional dan instrumental yang diberikan oleh keluarga atau teman, memperkuat perilaku idola mereka tetapi mereka juga menerima intimidasi dari pasangan sekolah mereka karena idola K-pop mereka terlihat sangat feminin. Fanatisme peserta terhadap idola diperkuat dan menyebabkan kondisi yang disebut internalisasi. Kondisi internalisasi ini
\end{abstract}


membuat mereka memiliki fantasi seksual terhadap idola dan keyakinan bahwa idola adalah pacar mereka.

Kata kunci: proses idolisasi; fenomenologis; K-pop; idola; makna dan keyakinan; fantasi.

\section{Pendahuluan}

Fenomena penggemar sebenarnya sudah dari dulu menjadi bahan pembicaraan orang-orang di seluruh dunia. Dimulai dari kemunculan musik-musik barat seperti Boyz II Men, Westlife, Pussycat Dolls di Amerika membawa pengaruh ke beberapa penjuru dunia. Mereka menyuguhkan penampilan yang apik serta lagu yang mudah diikuti. Di Korea sendiri, boyband dan girlband pun juga sudah ada sejak era 1990an, dimulai dari FIN.kl dan Sech Skies contohnya, membawa pengaruh terhadap keeksisan boyband Korea sampai sekarang dan membuatnya mendunia. Dimana ada idola, di situ ada penggemar. Penggemar dikatakan mengalami gejolak emosi terhadap apapun yang dilakukan oleh idolanya. Menangis, berteriak histeris, rasa penasaran atas apa yang dilakukan idolanya adalah hal yang wajar bagi mereka. Apa yang sebenarnya membuat mereka merasa 'terikat' dengan idolanya?

Pada umumnya, orang akan merasa terikat secara emosional jika orang itu adalah, misal, anggota keluarga, namun lain hal nya dengan seorang penggemar. Mereka ternyata memiliki jenis hubungan yang sangat kuat dengan idola mereka. Merasa idolanya adalah kekasih dan segalanya bagi mereka, adalah hal yang wajar. Hubungan ini menurut Ballatine dan Martin adalah hubungan para-sosial, seperti layaknya hubungan atau interaksi dari fans dengan idola mereka, di mana fans merasa sangat terkoneksi dengan idolanya, tetapi idola mereka mungkin bahkan tidak mengenal mereka (Ketsoglou, 2012).

Dua informan dari penelitian ini adalah dua dari sekian juta penggemar k-pop yang ada di dunia. Setidaknya satu dari 6,8 juta penggemar k-pop di Asia. Data ini diperoleh dari koreatimes.co.kr yang menyatakan bahwa Asia dan Oseania menempati urutan pertama di dunia 
dengan jumlah penggemar k-pop terbanyak pada tahun 2013, diikuti oleh Amerika, Eropa, Afrika dan Timur-tengah. Mereka sama-sama menghayati sang idola sebagai kekasihnya dan bahkan muncul fantasifantasi seksual. Melalui pengalaman informan tersebut, orang mungkin akan terfikir bahwa hal tersebut tidak wajar. Kehadiran selebriti itu sendiri sebenarnya bisa menimbulkan euforia pada seorang penggemar, seperti contohnya menangis (Ketsoglou, 2012). Peneliti menganggap hal tersebut menarik karena itu adalah proses dari awal hingga sampai mereka memaknai idolanya sedemikian rupa hingga mereka merasa sangat terikat dengan idola mereka masing-masing.

Penelitian ini menggunakan paradigma interpretatif. Melalui penelitian yang akan dilakukan ini peneliti akan berusaha menggali proses bagaimana individu menjadi seorang penggemar. Paradigma interpretif ini jika dilihat dari buku Guba dan Lincoln menyatakan bahwa paradigma ini berusaha memahami realita yang merupakan hasil dari rekonstruksi yang spesifik individu. Kehadiran partisipan dianggap penting karena partisipan berlaku sebagai fasilitator untuk merekonstruksi berbagai 'suara' (Guba \& Lincoln, 1994). Melalui paradigma ini peneliti nantinya akan menyuarakan hasil yang didapat dari informan.

Penelitian ini menggunakan pendekatan fenomenologi. Penelitian jenis ini dilakukan untuk menyelidiki pengalaman manusia dan menjelaskan fenomena apa yang akan diangkat dalam penelitian ini. Konsep utama dari pendekatan jenis ini adalah makna, yaitu bahwa makna merupakan sebuah esensi yang penting dan muncul dari pengalaman kesadaran manusia. Fenomenologi juga meneliti berdasarkan refleksi dari pengalaman langsung atau refleksi terhadap sebuah gejala (fenomena). Sudut pandang diperoleh dari sudut pandang pertama yaitu dari orang yang mengalami peristiwa (fenomena) itu sendiri (Hajaroh, 2010).

Data yang nantinya diperoleh peneliti akan di analisa menggunakan Intrepretative Phenomenological Analysis (IPA) yang di 
perkenalkan oleh Jonathan A. Smith. Smith dan Osborn mengatakan bahwa IPA memiliki tujuan untuk mengungkap bagaimana informan memaknai dunia personal dan sosialnya secara detail (Smith \& Osborn, 2007).

\section{Hasil dan Pembahasan}

Analisis data melalui beberapa tahap, yaitu: a) mengumpulkan data yang sudah ada; b) membaca dan mengelompokkan melalui tema-tema yang muncul; dan c) intrepretasi.

Informan pertama adalah Al (21 Tahun) merupakan remaja perempuan yang mempunyai idola bernama Hyukjae yang berasal dari Super Junior. Informan kedua adalah Bt (19 Tahun) merupakan remaja perempuan yang mempunyai idola bernama Chanyeol yang berasal dari EXO. Mereka berdua mengatakan awalnya sama sekali tidak ada ketertarikan dengan musik k-pop sebelumnya.

\section{a) Informan Pertama Al (21 Tahun)}

Al mengatakan bahawa yang pertama kali mengenalkan musik padanya adalah ibunya. Ibu Al tidak hanya mengenalkan, tetapi juga turut mendukung hobi musik anak dengan selalu membelikannya kaset musik seperti Hadad Alwi, Westlife, Adam Lambert, Jonas Brother dan lainlainnya. Al lalu mulai mengenal K-pop, karea temannya selalu menunjukkan idolanya tersebut kepadanya, hingga pada suatu saat ketika Super Junior datang ke Indonesia hingga banyak media banyak meliput, Al mulai penasaran dan akhirnya rasa sukanya bertahan sampai sekarang. Hobi mendengarkan musik itu bisa bertahan sampai sekarang karena mendapatkan reinforcement atau penguatan berupa terus di fasilitasi atau di belikan CD kaset, novel dan diperbolehkan menonton konser jika idolanya mampir ke Indonesia. Teori ini dipopulerkan oleh B.F Skinner, menjelaskan bahwa konsekuensi yang muncul dari sebuah perilaku memang mempengaruhi bagaimana kelanjutan dari perilaku tersebut, bisa merupakan konsekuensi yang sifatnya positif ataupun negatif (Santrock, 
2011). Dalam hal ini, Al mendapatkan konsekuensi yang sifatnya positif, yaitu terus mendapatkan dukungan dari hobi musiknya oleh orang tua, yang mana akan secara otomatis menguatkan perilakunya.

Idola yang menjadi favorit Al adalah Hyukjae dari Super Junior. hal yang membuat Al jatuh hati pada Hyukjae adalah bagaimana idolah tersebut berdansa dengan luwes, meskipun secara penampilan fisik Hyukjae masih kalah dengan anggota lain, menurut Al hal itu bukanlah hal yang penting. Hal yang menarik ditemukan pada Al selama proses wawancara berlangsung, bahwa ia tidak hanya menganggap Hyukjae adalah sosok idola biasa yang dikagumi karena karya yang telah dibuat selama menjadi anggota dari Super Junior, tetapi Al menganggap Hyukjae selama ini adalah sosok kekasihnya. Peneliti juga menemukan fakta bahwa rasa suka Al terhadap Hyukjae ternyata mempengaruhi kriteria pemilihan pasangan hidupnya. Alinda mengatakan bahwa awalnya ia ingin menikah dengan Hyukjae, namun seiring berjalannya waktu, Al lebih menekankan kepada pasangan yang memiliki sifat atau karakteristik yang mirip dengan idolanya itu.

Pada suatu saat, Hyukjae terkena skandal dimana dikabarkan berpacaran dengan salah satu artis asal Korea lain. Kabar ini membuat hati Al tersayat hingga menangis. Tidak hanya kabar yang menyatakan bahwa Hyukjae telah memiliki pasangan saja yang membuat Al sakit hati, namun ia merasa bahwa 'kekasih'nya itu tak sepantasnya mendapat komentar negatif dari netizen Korea Selatan. Al mengatakan bahwa ia merasa seperti dikhianati dan diselingkuhi oleh kekasihnya sendiri.

Selama menjadi penggemar musik K-pop, Al mendapatkan berbagai dukungan dari orang sekitarnya, dalam hal ini ibu dan saudara serta teman-teman dekat Al. Ibu dari Al memberikan dukungan secara emosional dan instrumental, yaitu dukungan secara finansial. Saudara Al memberikan dukungan secara emosional dan temannya memberikan dukungan secara emosional dan instrumental. Dukungan ini didefinisikan Gottlieb sebagai sebuah timbal balik yang diwujudkan dalam bentuk 
dukungan oleh seseorang yang bermakna bagi individu tersebut (Brieger, 2006). Brieger menyebutkan dukungan ini bisa dalam berbagai bentuk, yaitu emosional, instrumental, informasional dan penghargaan atas sesuatu. Bentuk dari dukungan emosional adalah afeksi, pengakuan dan kekhawatiran, dukungan instrumental berupa uang dan waktu, dukungan informasional bisa berupa sugesti, saran dan informasi, dan yang terakhir yaitu dukungan berupa penghargaan biasanya berupa timbal balik dan afirmasi atas suatu hal. Respon dari significant others atau orang yang relevan bagi individu tersebut disebut sebagai salah satu faktor penguat yang membuat sebuah tindakan akan terulang atau tidak (Brieger, 2006).

Al sendiri mengatakan bahwa setelah menyukai K-pop, dia menjadikan musik K-pop sebagai coping nya ketika dia sedang stress, tertekan maupun putus asa. Menurut Lazarus dan Folkman, proses coping stres memiliki dua bentuk, yaitu problem solving dan bentuk emotional focused yang menekankan pada pengaturan konsekuensi-konsekuensi emosional dari kejadian yang menimbulkan stress (Lazarus, 1993). Di dalam dua kategori besar tersebut, masih terbagi lagi menjadi 8 jenis. Confrontive Coping, Seeking Social, Support, Planful Problem-Solving, SelfControlling, Escape-Avoidance, Distancing, Positive Reappraisal, Dan Accepting Responsibility (Lazarus, 1993). Strategi coping Al yang 'lari' ke musik K-pop ketika dia sedang tertekan dan stres menunjukkan adanya coping dengan jenis distancing yang mana pengertiannya adalah individu menggambarkan sebuah usaha melepaskan diri dari situasi yang membuatnya stres, menciptakan pandangan positif dan mencoba menenggalamkan diri dalam kegiatan lain untuk melepaskan pikiran dari masalah yang dihadapi (Lazarus, 1993).

\section{b) Informan Kedua Bt (19)}

Bt mengaku bahwa ketika sebelum mengenal K-pop, ia tidak terlalu mengikuti perkembangan musik barat seperti Westlife ataupun musik Indonesia. Dia hanya menyebutkan bahwa dulu mengenal musik karena adanya acara-acara musik di TV Indonesia, seperti Dahsyat 
yang seringkali memutar lagu seperti grup band Ungu, lalu sempat booming juga tren musik India namun dia tidak seberapa mengikuti itu. Bt lalu mengetahui K-pop karena teman SMP dan SMA nya suka mendengarkan lagu K-pop.

Idola favorit dari Bt adalah Chanyeol dari EXO. Bt menyukai Chanyeol karena ketampanannya, namun ternyata ketampanan Chanyeol bukan hanya sebagai penentu satu-satunya bagaimana $\mathrm{Bt}$ bisa jatuh hati padanya, namun bagaimana karateristik Chanyeol yang konyol, lalu ditambah dengan suaranya yang berat yang diibaratkan oleh Bt sebagai suara yang 'seksi'. Bt juga memaknai Chanyeol ini sebagai sosok kekasihnya, dia bahkan mengatakan kepada peneliti bahwa Chanyeol dan dirinya adalah sepasang kekasih yang menjalin hubungan jarak jauh (Long Distance Relationship).

Hal yang sama dirasakan oleh Bt, yaitu ketika Chanyeol dikabarkan tengah berpacaran dengan idola wanita yang lain, ia merasa sakit hati pada saat itu. Bukan hanya karena idolanya dikabarkan berkencan, namun terlebih karena hujatan yang dilontarkan netizen Korea saat itu kepada Chanyeol. Ia mengatakan bahwa netizen tidak berhak berkomentar demikian kepada idolanya itu karena itu menyangkut kehidupan pribadi idolanya. Kejadian selanjutnya yang membuat insting 'kekasih' dari Bt ini merasa teruji adalah ketika Chanyeol mendapatkan bagian dalam sebuah film, yang mengharuskan dirinya melakoni kissing scene atau adegan ciuman dengan perempuan lain. Bt merasa sakit hati karena dia merasa dikhianati oleh pacar sendiri, seolah-olah Chanyeol itu adalah pacarnya dan sedang berciuman dengan perempuan lain di depan wajahnya, lalu apakah hanya rasa sakit hati saja yang dirasakan oleh Bt?. Ternyata tidak, Bt mengatakan sanking sakit hatinya melihat pemberitaan yang terus menerus muncul di beranda Line miliknya, $\mathrm{Bt}$ mengatakan vakum sejenak dari media sosial untuk menghindari pemberitaan tentang adegan kissing scene yang dilakoni oleh Chanyeol tersebut, 
dengan cara mengubah foto profil di Linenya menjadi warna hitam, lalu keluar dari segala grup k-pop yang ia ada di dalamnya.

Hal yang menarik dari Bt adalah bagaimana ia suka memasangkan Chanyeol dengan anggota EXO yang lain, yaitu Baekhyun. Tidak hanya memasangkan, Bt memaknai mereka sebagai sosok yang benar-benar berpacaran di dunia nyata. Bt sering membayangkan mereka benar-benar berhubungan intim di balik kamera karena sangat banyak bukti-bukti berupa foto dan video yang menunjukkan kemesraan mereka berdua.

Selama menjadi penggemar musik K-pop, Bt juga mendapatkan berbagai dukungan dari orang sekitarnya, dalam hal ini ibu dan temanteman dekatnya. Ibu dari Bt memberikan dukungan secara emosional dan instrumental, yaitu dukungan secara finansial, sedangkan temannya memberikan dukungan secara emosional.

\section{Persamaan Al (21) dan Bt (19)}

Seorang penggemar pada dasarnya hanya bisa berinteraksi dengan idola favoritnya melalui media, entah itu melalui televisi ataupun gadget dan melalui media sosial. Jenis hubungan ini disebut hubungan "parasosial". Hubungan ini didefinisikan oleh Ballatine \& Martin seperti layaknya hubungan atau interaksi dari fans dengan idola mereka, dimana hubungan ini disadari dan dibangun oleh satu pihak namun pihak yang lainnya tidak menyadari itu (Ketsoglou, 2012). Hubungan ini bersifat lebih 'intim' dan berbeda dengan jenis- jenis hubungan yang lain, hal yang membedakannya, yaitu adalah adanya 'jarak' yang membuat sebagian besar penggemar idola tersebut bahkan tidak pernah secara langsung bertemu. Dimulai dari media yang mengekspos kehidupan selebriti, penonton menjadi seolah tahu akan kehidupan selebriti favorit mereka mulai dari penampilan, gestur, gaya percakapan, filosofi yang dicetuskan, dan gaya berfikir meskipun tidak pernah berbicara langsung dengan idola mereka tersebut (Canizares, 2015).

Menurut beberapa studi oleh Maltby et al., ada beberapa jenis dari pemujaan idola beserta kriteria hubungan yang dimiliki fans terhadap 
selebriti favoritnya. Jenis yang pertama adalah entertainment- social dimana pada hubungan jenis ini, penggemar hanya melihat selebriti sebagai pemenuhan kebutuhan hiburan saja. Penggemar mempunyai tingkat keingin-tahuan terhadap selebriti favoritnya yang cukup normal dan perilaku tersebut sudah termasuk mencari info dan kabar terbaru lalu menjadikannya bahan pembicaraan. Jenis yang kedua dinamakan intense-personal dimana penggemar biasanya akan merasa mempunyai koneksi yang intens atau hubungan yang kuat secara personal dengan selebriti favorit mereka dan bahkan menganggap idola mereka sebagai soulmate. Jenis hubungan yang terakhir adalah borderline-pathological dimana jenis hubungan ini dikatakan jenis yang cukup "parah", dimana para penggemar memiliki obsesi dengan detail kehidupan selebriti favorit mereka. Mereka juga mempunyai kepercayaan dimana ia dan idola mereka bisa berkomunikasi melalui sebuah kode rahasia. Dipercaya jenis hubungan yang terakhir ini bisa mengganggu dan merusak perkembangan psikologis (Liu, 2013). Al (21) dan Bt (19) berada pada jenis hubungan yang kedua, yaitu intense-personal dimana mereka menganggap bahwa idola mereka sebagai seorang kekasih.

\section{Kesimpulan Dan Saran}

\section{Kesimpulan}

Kesimpulan pertama, yaitu semua penggemar musik, musik apapun, namun khususnya dalam penelitian ini, yaitu penggemar musik K-pop, memiliki perbedaan perjalanan mereka masing-masing. Para penggemar musik K-pop pada umumnya tidak langsung mengenal musik K-pop ketika masih belia, namun dimulai dari adanya interest terhadap musik terlebih dahulu, setelah itu hobi musik mereka akan baru muncul terhadap jenis musik spesifik tertentu, dalam hal ini, yaitu musik K-pop.

Kesimpulan kedua, hobi musik penggemar K-pop tidak lepas dari dukungan dari keluarga, dalam penelitian ini khususnya ibu dan saudara. Dukungan tersebut bisa berupa dukungan emosional dan dukungan 
instrumental, seperti dukungan berupa uang dan fasilitas. Hambatan juga dialami pada umumnya oleh penggemar K-pop. Pada penelitian ini khususnya ditemukan adanya kesamaan antara kedua informan, yaitu sosok ayah dalam kehidupan mereka sama-sama tidak mendukung hobi musik anak.

Kesimpulan ketiga, dukungan ibu pada penelitian ini bisa digolongkan sebagai sebuah reinforcement, yang mana terbukti menguatkan hobi penggemar music K-pop tersebut. Hal ini dikarenakan kehadiran ibu yang juga merupakan significant others bisa lebih menguatkan lagi dan membuat sebuah perilaku lebih cenderung akan berulang dibandingkan dengan dukungan dari orang lain.

Kesimpulan keempat, kehadiran K-pop yang sebenarnya tidak terlalu diterima di kalangan remaja Indonesia membuat beberapa penggemarnya merasa kesulitan dalam proses idolisasi yang mereka lalui. Hal ini terjadi dengan bentuk perlakuan tidak menyenangkan seperti bullying dan mendapat perlakuan sinis dari teman karena dianggap hanya membuang-buang uang saja.

Kesimpulan kelima, hobi musik kedua informan yang makin ditekuni oleh mereka memunculkan rasa fanatisme. Fanatisme ini berbentuk euforia dan berbagai bentuk ledakan emosional, seperti rasa bahagia, rasa bersyukur dan bahkan rasa sedih dan kecewa. Fanatisme ini pun berujung pada penghayatan penggemar k-pop yang meyakini bahwa idolanya adalah kekasihnya. Hal ini tidak diyakini sebagai hal yang bercanda saja namun sudah melewati proses internalisasi, yang menyebabkan munculnya fantasi dan imajinasi yang sifatnya sungguh-sungguh, contohnya ketika idola mereka terkait kasus dikabarkan tengah menjalin hubungan asmara dengan idola lain, mereka sontak menangis mendengar kabar itu dan berusaha menutup segala akses di media social yang mereka miliki agar sejenak bisa terhindar dari artikel berita tersebut karena merasa mereka telah 
diselingkuhi oleh kekasihnya sendiri, yakni idolanya. Saran

Peneliti menyadari bahwa dalam penellitian ini masih mengandung banyak kekurangan, maka dari itu peneliti akan memberikan saran yang bisa dilakukan peneliti lainnya pada topik serupa ke depannya.

Pertama, penelitian ini dilakukan hanya pada informan berjenis kelamin perempuan. Faktanya, penggemar musik, khususnya musik Kpop, juga memiliki penggemar yang berjenis kelamin laki-laki. Untuk penelitian selanjutnya, akan lebih baik juga menggunakan informan laki-laki untuk memperkaya data, terutama mengenai penghayatan informan terhadap idolanya.

Kedua, penelitian ini menggunakan metode kualitatif, yakni fokus pada proses idolisasi para informan. Metode kuantitatif bisa digunakan sebagai alternatif metode dalam topik penelitian idolisasi ini, khususnya jika anda ingin membandingkan fanatisme antar subjek/informan.

Ketiga, pada penelitian ini, kredibilitas data diperoleh dengan menggunakan triangulasi teori. Informan yang tidak bersedia dilakukannya wawancara terhadap significant person nya membuat data kurang kaya. Akan lebih sempurna jika pada penelitian selanjutnya dilakukan triangulasi data, dimana significant person, seperti orang tua atau saudara juga mendapatkan giliran wawancara agar data yang diterima semakin kuat.

Keempat, proses internalisasi yang dialami informan menyangkut fantasi terhadap idolanya dianggap kurang didapatkan oleh saya sebagai peneliti, ini dikarenakan topik yang sensitif, membuat informan kurang terbuka terhadap peneliti. Pada penelitian selanjutnya, diharapkan jalinlah rapport yang baik dengan informan anda, agar informasi yang didapatkan lebih kaya lagi.

\section{DAFTAR PUSTAKA}

Brieger, W. R. (2006). Social Support. Bloom Berg School of Public Health 
Journal, 1-34.

Canizares, E. (2015). Celebrity Worship: A Sociological Study of Celebrity Worship as A Contemporary Religion. 1- 42.

Guba, E., \& Lincoln, Y. (1994). Handbook of Qualitative Research. Thousand Oaks, California: Sage.

Hajaroh, M. (2010). Paradigma, Pendekatan dan Metode Penelitian Fenomenologi. 1-21.

Ketsoglou, E. (2012). When Good Celebrities "Go Bad": Examining Celebrity Worship. Journal of Psychology Research Proposals, 17-21.

Lazarus, R. (1993). Coping Theory and Research : Past, Present and Future. Psychosomatic Medicine, 234-247.

Liu, J. K. (2013). Idol Worship, religiousity, and self esteem among university and secondary students in Hong Kong. SS Student EJournal, 15-28.

Santrock, J. W. (2011). Educational Psyhocology / John Santrock 5th ed. . Dalam J. W. Santrock, Educational Psyhocology/John Santrock 5th ed. New York: MCGraw-Hill Companies, Inc.

Smith, J.A., \& Osborn, M. (2007). IntrepretativPhenomenological Analysis. 